\title{
Combined effect of sodium selenite and docetaxel on PC3 metastatic prostate cancer cell line
}

\author{
Mariana Freitas $^{\mathrm{a}, \mathrm{b}, \mathrm{c}, *}$, Vera Alves ${ }^{\mathrm{d}, 1}$, Ana Bela Sarmento-Ribeiro ${ }^{\mathrm{b}, \mathrm{c}, \mathrm{e}, 2}$, Anabela Mota-Pinto ${ }^{\mathrm{a}, \mathrm{b}, 3}$ \\ ${ }^{a}$ General Pathology Laboratory, Faculty of Medicine, University of Coimbra, Rua Larga, 3004-504 Coimbra, Portugal \\ ${ }^{\mathrm{b}}$ CIMAGO - Centre of Investigation in Environment, Genetics and Oncobiology, Faculty of Medicine, University of Coimbra, Apartado 9015, 3001-301 Coimbra, Portugal \\ ${ }^{\mathrm{c}} \mathrm{CNC}$ - Centre of Neurosciences and Cell Biology, Department of Zoology, University of Coimbra, 3004-517 Coimbra, Portugal \\ ${ }^{\mathrm{d}}$ Immunology Laboratory, Faculty of Medicine, University of Coimbra, Rua Larga, 3004-504 Coimbra, Portugal \\ ${ }^{\mathrm{e}}$ Applied Molecular Biology/Biochemistry Laboratory, Faculty of Medicine, University of Coimbra, Subunidade I de Ensino, Pólo III, $3000-354$ Coimbra, Portugal
}

\section{A R T I C L E I N F O}

Article history:

Received 21 April 2011

Available online 28 April 2011

\section{Keywords:}

Prostate cancer

Docetaxel

Sodium selenite

Synergistic effect

Chemotherapy

\begin{abstract}
A B S T R A C T
Docetaxel and sodium selenite are well known for their anticancer properties. While resistance to docetaxel remains an obstacle in prostate cancer chemotherapy, sodium selenite, has been exploited as a new therapeutic approach. Currently, development of therapies affecting a multitude of cell targets, have been proposed as a strategy to overcome drug resistance. This association may reduce systemic toxicity counteracting a wide range of side effects.

Here we report the effect of docetaxel and sodium selenite combination on the PC3 prostate cancer cell line, derived from bone metastasis. Therefore we evaluate cell growth, cell cycle progression, viability, mitochondria membrane potential, cytochrome $\mathrm{C}, \mathrm{Bax} / \mathrm{Bcl} 2$ ratio, caspase- 3 expression and reactive oxygen species production.

Our results suggest that sodium selenite and docetaxel combination have a synergistic effect on cell growth inhibition (67\%) compared with docetaxel (22\%) and sodium selenite (24\%) alone. This combination also significantly induced cell death, mainly by late apoptosis $v s$ necrosis, which is correlated with mitochondria membrane potential depletion. On the other hand, cytochrome $\mathrm{C}, \mathrm{Bax} / \mathrm{Bcl} 2$ ratio and caspase-3, known as proapoptotic factors, significantly increased in the presence of sodium selenite alone, but not in the presence of docetaxel in monotherapy or in combination with sodium selenite.

These findings suggest that docetaxel and sodium selenite combination may be more effective on prostate cancer treatment than docetaxel alone warranting further evaluation of this combination in prostate cancer therapeutic approach.
\end{abstract}

\section{Introduction}

Prostate carcinoma is the most commonly diagnosed malignancy and the second leading cause of cancer-related mortality in men in the Western Countries [1,2].

Besides clinical and scientific efforts on prostate cancer, conventional therapies fail to eliminate advanced tumors. As prostate cancer cell growth is androgen dependent, its deprivation is an important therapeutic strategy. However, long-term androgen-

\footnotetext{
* Corresponding author at: General Pathology Laboratory, Faculty of Medicine, University of Coimbra, Rua Larga 3004-504 Coimbra, Portugal. Fax: +351 239822 547.

E-mail addresses: freitas.mariana@gmail.com (M. Freitas),valves@fmed.uc.pt (V. Alves), ana.belasarmento@gmail.com (A.B. Sarmento-Ribeiro), apinto@fmed.uc.pt (A. Mota-Pinto).

1 Fax: +351239820242

2 Fax: +351239480048

3 Fax: +351239822 547
}

ablation results in androgen-independent cancer cell growth in metastatic patients, leading to hormone refractory prostate cancer (HRPC) [3].

Chemotherapy, using Taxotere (docetaxel), a member of taxane family remains the standard option for patients at the advanced stages, namely in the HRPC [4]. Docetaxel binds to microtubules and promotes their polymerization, assembly and stabilization, inhibiting mitosis and cell cycle progression via G2M phase arrest. It also down regulates the anti-apoptotic Bcl-2 expression [4-9], enhances the apoptosis induced by "tumor necrosis factor-related apoptosis-inducing ligand" (TRAIL) [8], down regulates genes involved in cell cycle progression (cyclin A, cyclin $\mathrm{F}, C D C 2, C D K 2$, $B T G$, etc.), transcription factors (transcription factor A, ATF5, TAF $131 \mathrm{~L}$, etc.), oncogenes (GRO, BRCA1, p120, etc.) and apoptosis as GADD45A [6-9]. However, cancer cells become resistant and therefore docetaxel therapy is limited. Makarovskiy et al. [10] found that continuity of drug exposure induces the formation of resistant giant multinucleated clones. 
On the other hand, selenium is an essential trace element that has generated considerable interest in prostate cancer chemoprevention. This protective effect results from a combination of various mechanisms as the prevention of DNA damage, oxidative stress and inflammation. It may also activate enzyme detoxification mechanisms by selenoproteins activation as glutathione peroxidase (Gl-Ppx) (for review see Nadiminity and Gao [11]).

Nevertheless, recent studies demonstrate that higher selenium concentrations have anticancer activity by inducing cell growth inhibition and apoptosis on prostate cancer cells [12-16] concomitantly with an increase in $\mathrm{Bax} / \mathrm{Bcl} 2$ ratio, Bak and Bid proteins and decrease in $\mathrm{Bcl} 2$ expression [16].

Selenium related-apoptosis is induced by oxidative stress, resulting from antioxidant defenses depletion, namely, reduced glutathione/oxidized glutathione (GSH/GSSG), along with an increase of superoxide and hydrogen peroxide production in prostate cancer cells $[13,15]$. Moreover, sodium selenite $\left(\mathrm{Na}_{2} \mathrm{SeO}_{3}\right)$, an inorganic form of selenium, alters subcellular distribution of manganese superoxide dismutase (MnSOD), another important antioxidant defense, inducing its depletion in mitochondria and its increase in cytosol [17].

Menter et al. [12] found that sodium selenite is more potent than the organic selenomethionine (SeMet) form as an apoptotic inducer. Furthermore, Jiang et al. [18] demonstrated that the exposure of the androgen independent prostate cancer cells, DU145, to SeMet $v$ s sodium selenite induced differential patterns on cell cycle arrest and apoptosis, as well as distinct effects on AKT, ERK1/2, JNK1/2, and p38MAPK phosphorylation and p27kip1 and p21cip1 expression. Concomitantly, selenite exposure caused S-phase arrest and induced apoptotic DNA fragmentation caspase-independent, which were associated with the decrease of p27kip1 and p21cip1 expression and the increased of AKT, JNK1/2, and p38MAPK phosphorylation.

Lack of curative treatments at the advanced prostate cancer, underline the importance of additional trials for the successful development of an effective therapeutic approach. As it is clear that sodium selenite and docetaxel affects a multitude of targets instead of just one key, we are interested to evaluate if docetaxel and sodium selenite combination results in a synergistic anticancer effect that could contribute to lower systemic toxicity.

\section{Materials and methods}

\subsection{Cell culture conditions}

Human prostate cancer cell line, PC3, derived from bone metastasis [19] represents the advanced stages of this disease and was purchased from the American Type Culture Collection (ATCC).

Cell growth was performed in RPMI 1640 medium (Sigma) with $10 \%(\mathrm{v} / \mathrm{v})$ heat-inactivated fetal bovine serum (FBS) (Biochrom) and $2 \mathrm{mM}$ L-glutamine (Sigma), supplemented with $100 \mathrm{U} / \mathrm{ml}$ Penicillin, $100 \mu \mathrm{g} / \mathrm{ml}$ Streptomycin and with $5 \mu \mathrm{g} / \mathrm{ml}$ Kanamycin (Sigma). Cells were maintained in a $95 \%$ humidified incubator with $5 \% \mathrm{CO}_{2}$ at $37^{\circ} \mathrm{C}$, and were passaged with trypsinization every fourth day. For assays, PC3 were seeded in a concentration of $3 \times 10^{5}$ cells/ $\mathrm{ml}$. After being cultured up to $80 \%$ confluence, cells were washed once with fresh assay medium and treated for 24-72 h with the Sodium Selenite (Sigma) (10 nM to $5 \mu \mathrm{M}$ ) and/or docetaxel (Taxotere, Aventis) (5-250 nM) dissolved in 13\% (v/v) ethanol.

\subsection{Growth inhibition assays}

Cell proliferation was measured by the colorimetric MTT (3[4,5-dimethylthiazol-2-yl]-2,5-diphenyltetrazolium bromide) (Sigma) method that quantifies the reduction of the yellow tetrazolium salt to purple formazan crystals by the mitochondria of viable cells [20]. Briefly, after the treatment on 96-well plates, the cells were washed with $0.2 \mathrm{ml}$ of PBS (Gibco) and each well was replaced by $0.1 \mathrm{ml}$ of MTT $(0.5 \mathrm{mg} / \mathrm{ml})$ in medium salt $(132 \mathrm{mM} \mathrm{NaCl}$, $4 \mathrm{mM} \mathrm{KCl}, 1.2 \mathrm{mM} \mathrm{Na}_{2} \mathrm{HPO}_{4}, 6 \mathrm{mM}$ Glucose and $10 \mathrm{mM}$ Hepes buffer), supplemented with $1 \mathrm{mM} \mathrm{CaCl}_{2}$ (Sigma). Cells were then incubated at $37{ }^{\circ} \mathrm{C}$ for $2 \mathrm{~h}$. To each well was added $0.1 \mathrm{ml}$ of $0.04 \mathrm{M} \mathrm{HCl}$ in isopropanol to dissolve the formazan crystals. Optical density values, measured at $570 \mathrm{~nm}$ in a microplate reader (BioRad, Model 680 ) were use to determine the reduction of tetrazolium. IC $_{50}$ values were defined as the half maximal inhibitory concentration.

\subsection{Flow cytometry studies}

Flow cytometry studies were performed according to the following protocol: after $24 \mathrm{~h}$ incubation, $1 \times 10^{6}$ cells and corresponding controls were collected by trypsinization and washed two times in PBS buffer by centrifugation for further acquisition and analysis in a FACScalibur (488 and $635 \mathrm{~nm}$ ), using the Cellquest and Paint-a-gate software (BD Bioscience). At least 10,000 events were collected for viability and cell death, $\Delta \psi \mathrm{m}$, ROS (peroxides), cytochrome $\mathrm{C}$, caspase 3 analyses and $\mathrm{Bax} / \mathrm{Bcl} 2$ ratio determination, whereas, 20,000 events were collected for cell cycle assays.

\subsection{Cell cycle analyses}

Cell cycle distribution was assessed by analyses of DNA content [21,22] using a kit (Cytognos) with adaptations. Briefly, $1 \times 10^{6}$ cells were collected and treated with $1 \mathrm{ml}$ DNA labeling solution, containing detergent, propidium iodide and RNAse. Samples were then incubated in the dark for $10 \mathrm{~min}$, at room temperature in a horizontal position and immediately analyzed by flow cytometry.

\subsection{Cell death studies}

\subsubsection{Apoptosis and/or necrosis evaluation}

Identification of cell death by apoptosis and/or necrosis was performed after collecting total treated cells. Samples were labeled with Annexin-V (BD Biosciences) and propidium iodide (PI) (Invitrogen-Molecular Probes) according to the manufacture's instructions. After washed, $1 \times 10^{5}$ collected cells were resuspended in $100 \mu \mathrm{L}$ of binding buffer $(0.025 \mathrm{M} \mathrm{CaCl} 2,1.4 \mathrm{M} \mathrm{NaCl}, 0.1 \mathrm{M}$ Hepes $)$ containing $5 \mu \mathrm{L}$ of annexin-V APC and $2 \mu \mathrm{L}$ of propidium iodide (PI) $(3 \mu \mathrm{M})$ and then kept in the dark at room temperature for $15 \mathrm{~min}$. Cells were resuspended in a final volume of $500 \mu \mathrm{L}$ of binding buffer and were analyzed immediately by flow cytometry [23].

\subsubsection{Bax/Bcl2 ratio, cytochrome $C$ and caspase 3 assays}

Determination of $\mathrm{Bax}, \mathrm{Bcl} 2$, cytochrome $\mathrm{C}$ and caspase 3 were performed by flow cytometry after labeling the cells with monoclonal antibodies combined with fluorescent probes.

Cells were permeabilized and fixed with $250 \mu \mathrm{l}$ of cytofix-cytoperm (Cytofix/cytoperm kit, Pharmigen) for $20 \mathrm{~min}$ at $4{ }^{\circ} \mathrm{C}$ and washed with perm-wash (Cytofix/cytoperm kit), and centrifuged at $1500 \mathrm{rpm}$ for $5 \mathrm{~min}$.

Bax and Bcl2 antibodies were purchased from Santa Cruz Biotechnology and (pharmingen (BD)), respectively. Cells were labeled with $2 \mu \mathrm{g}$ Bax and $1 \mu \mathrm{g} \mathrm{Bcl} 2$ combined with phycoerythrin and fluorescein isothiocyanate (FICT), respectively, incubated for $15 \mathrm{~min}$ in the dark and then washed one time.

For caspase detection, cells were labeled with $2 \mu \mathrm{g}$ caspase antibody combined with phycoerythrin (pharmingen (BD)) followed by 45 min incubation in the dark. Cytochrome C, primary antibody $(0.5 \mu \mathrm{g})$ (Santa Cruz) was added to the cells followed by $15 \mathrm{~min}$ incubation in the dark and washed once. Cells were then labeled with $(0.5 \mu \mathrm{g})$ secondary antibody combined with phycoerythrin 
A

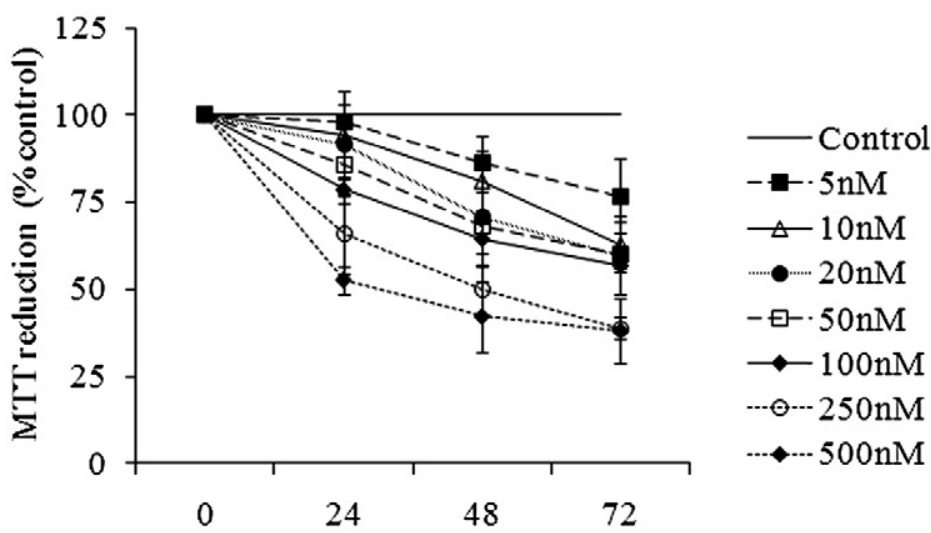

Time (h)
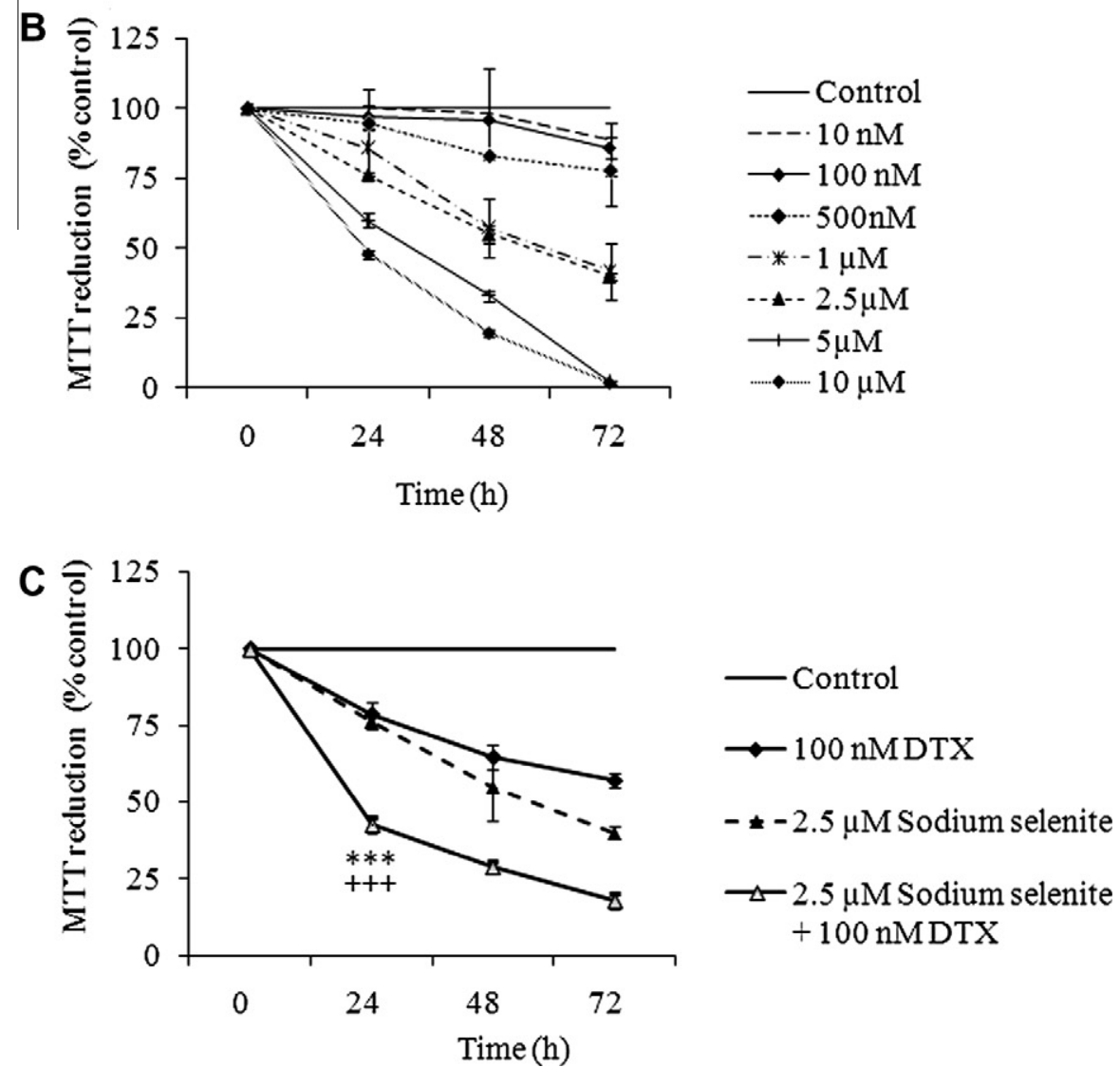

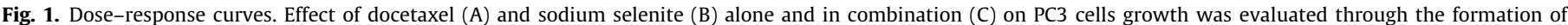

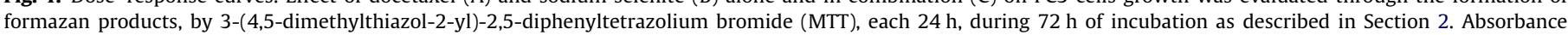

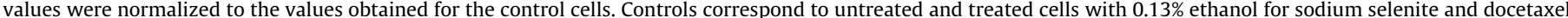

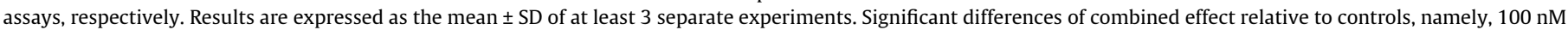
docetaxel and $2.5 \mu \mathrm{M}$ sodium selenite are considered for ${ }^{* * *} p<0.001$ and ${ }^{++} p<0.001$, respectively.

(Santa Cruz), for 20 min in the dark. After a wash step, cells were immediately analyzed by flow cytometry.

\subsection{Mitochondrial membrane potential ( $\Delta \psi \mathrm{\psi m})$ determination}

In order to detect $\Delta \psi \mathrm{m}$, attached cells, considered as the alive cells, were collected and then labeled with the fluorescent probe $5,5^{\prime}, 6,6^{\prime}$-tethrachloro-1,1'3,3'-tetraethylbenzimidazolylcarbocyanine iodide (JC1)(Cell Technology) according to manufacture's instructions. Briefly $5 \times 10^{5}$ cells were resuspended in $0.5 \mathrm{ml}$ of $1 \times$ $\mathrm{JC}-1$ reagent solution and then incubated during $15 \mathrm{~min}$, at $37^{\circ} \mathrm{C}$ in a $5 \% \mathrm{CO}_{2}$ chamber. Cells were washed two times with $2 \mathrm{ml} 1 \times$ assay buffer, resuspended in $0.5 \mathrm{ml} 1 \times$ assay buffer and were analyzed immediately by flow cytometry.

JC1 is a lipophilic cationic probe, developed by Cossariza et al. [24], able to cross the intact mitochondria membrane, forming Jaggregates (A), which are associated with a large shift in emission $(590 \mathrm{~nm})$. However, in lower polarized mitochondrial membrane, 


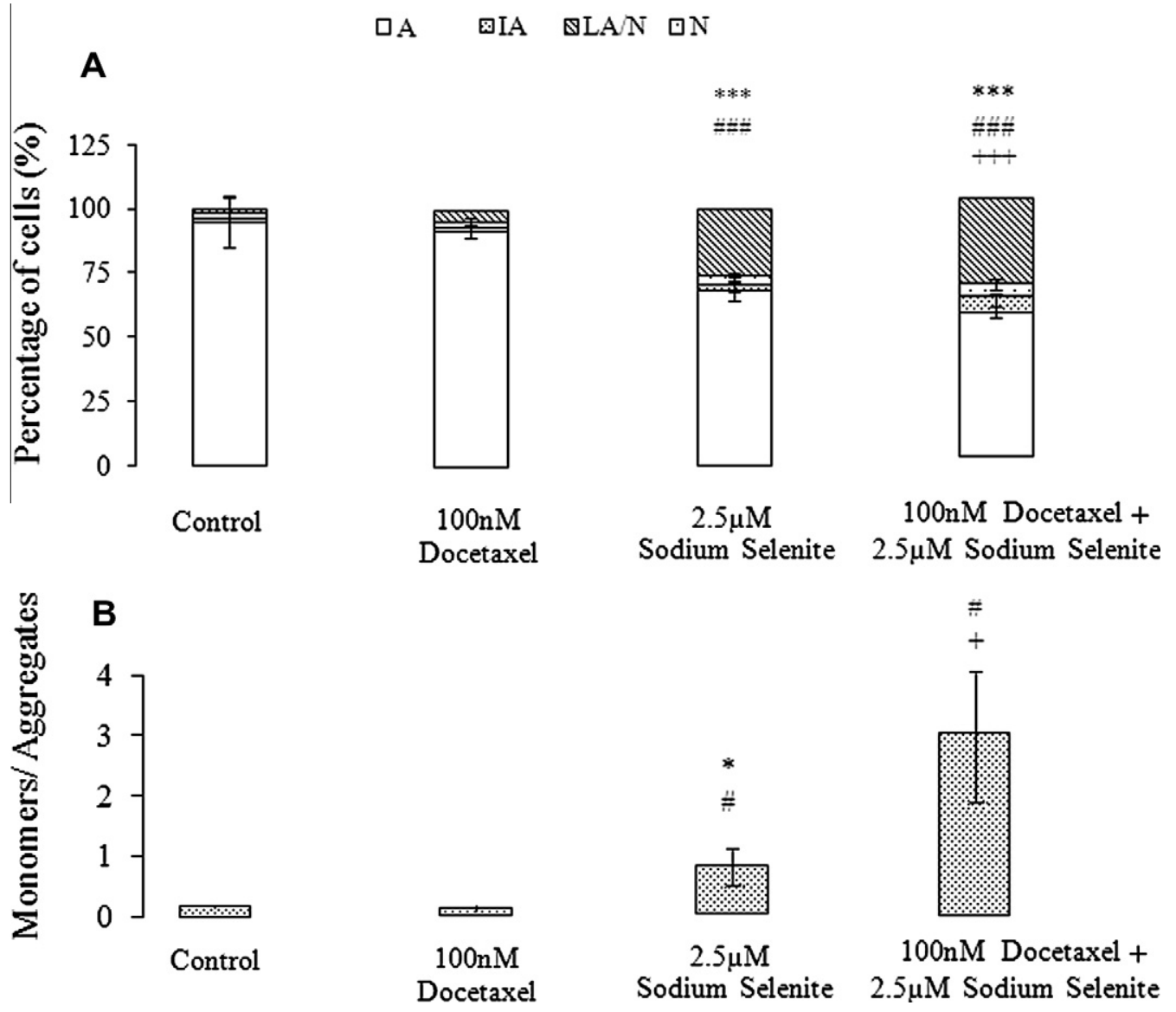

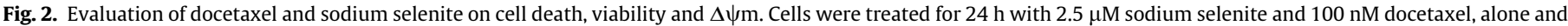

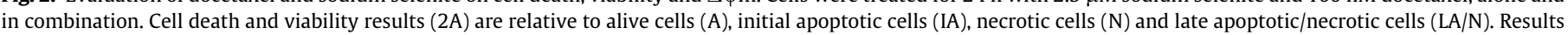

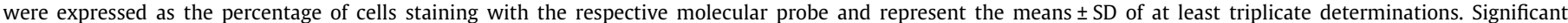

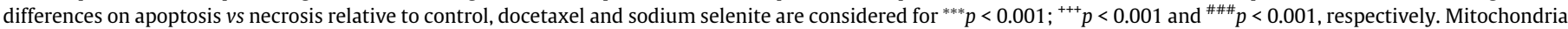

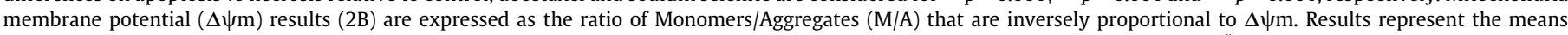

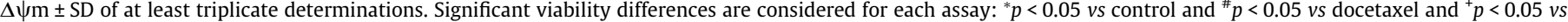
sodium selenite.

JC1 accumulates in the cytoplasm in the monomeric form (M) emitting at $527 \mathrm{~nm}$ upon excitation at $490 \mathrm{~nm}$. The ratio between $\mathrm{M} / \mathrm{A}$ is inversely correlated with the $\Delta \psi \mathrm{m}$.

\subsection{Reactive oxygen species (peroxides) determination}

Intracellular levels of peroxides were quantified labeling $5 \times 10^{5}$ cells with $5 \mu \mathrm{M}$ 2,7-dichlorofluorescein diacetate $\left(\mathrm{DCFH}_{2^{-}}\right.$ DA) (Sigma) according to Rothe and Valet [25] adaptations. Briefly, cells were incubated during $1 \mathrm{~h}$ at $37^{\circ} \mathrm{C}$, in the dark, washed 2 times in $0.5 \mathrm{ml}$ phosphate-buffered saline (PBS), resuspended in $0.5 \mathrm{ml}$ PBS and immediately analyzed by flow cytometry.

This methodology is based on the conversion of $\left(\mathrm{DCFH}_{2}-\mathrm{DA}\right)$ to $\mathrm{DCFH}_{2}$ by intracellular esterases that is consequent converted in the highly fluorescent 2,7-dichlorofluorescein (DCF) by ROS. The resultant green fluorescence is proportional to the intracellular level of ROS, upon excitation at $488 \mathrm{~nm}$.

\subsection{Statistical analyses}

All the data are expressed as mean \pm SD of the indicated number of experiments. Significance was assessed for $P$ values $<0.05$ according to $T$-tests.
Cell proliferation dose-response curves were fitted to 3 parameter sigmoid equation through computer-assisted curve fitting (SigmaPlot $\left.^{\circledR} 11.0\right)$.

\section{Results}

\subsection{Antiproliferative effect of docetaxel and sodium selenite on prostate cancer cells}

Docetaxel and sodium selenite inhibit prostate cancer cells (PC3) growth in a dose and time dependent-manner.

Half maximal inhibitory concentration values (IC50) of docetaxel (Fig. 1A) and sodium selenite (Fig. 1B) were reached for approximately $500 \mathrm{nM}$ (Rsqr: 0.998) and $10 \mu \mathrm{M}$ (Rsqr: 0.991), respectively, after $24 \mathrm{~h}$ incubation. However, when we treat the cells with $100 \mathrm{nM}$ docetaxel and $2.5 \mu \mathrm{M}$ sodium selenite simultaneously, we observed a synergistic antiproliferative effect (Fig. 1C). In fact, sodium selenite and docetaxel combination have a synergistic effect on cell growth inhibition (67\%) compared with docetaxel (22\%) and sodium selenite (24\%) alone. Interestingly, selenite and docetaxel induced synthesis (S) and G2M phase arrest respectively, while, the combination drugs induced $\mathrm{G} 2 \mathrm{M}$ and $\mathrm{S}$ phase arrest simultaneously, reflecting a synergistic effect (Table 1). 
A

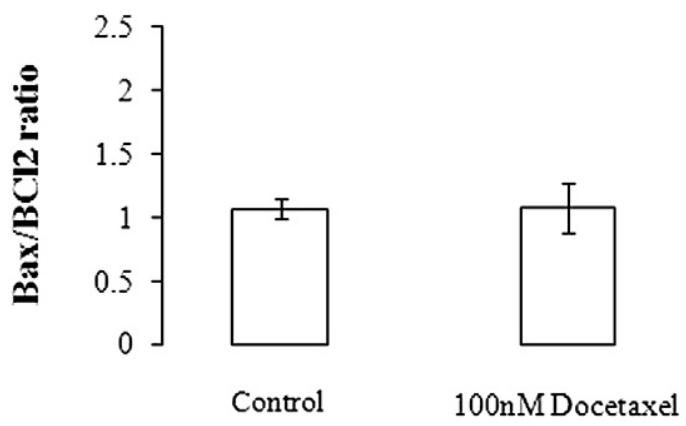

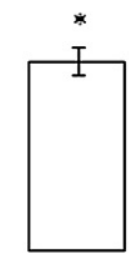

$2.5 \mu \mathrm{M}$ Sodium Selenite
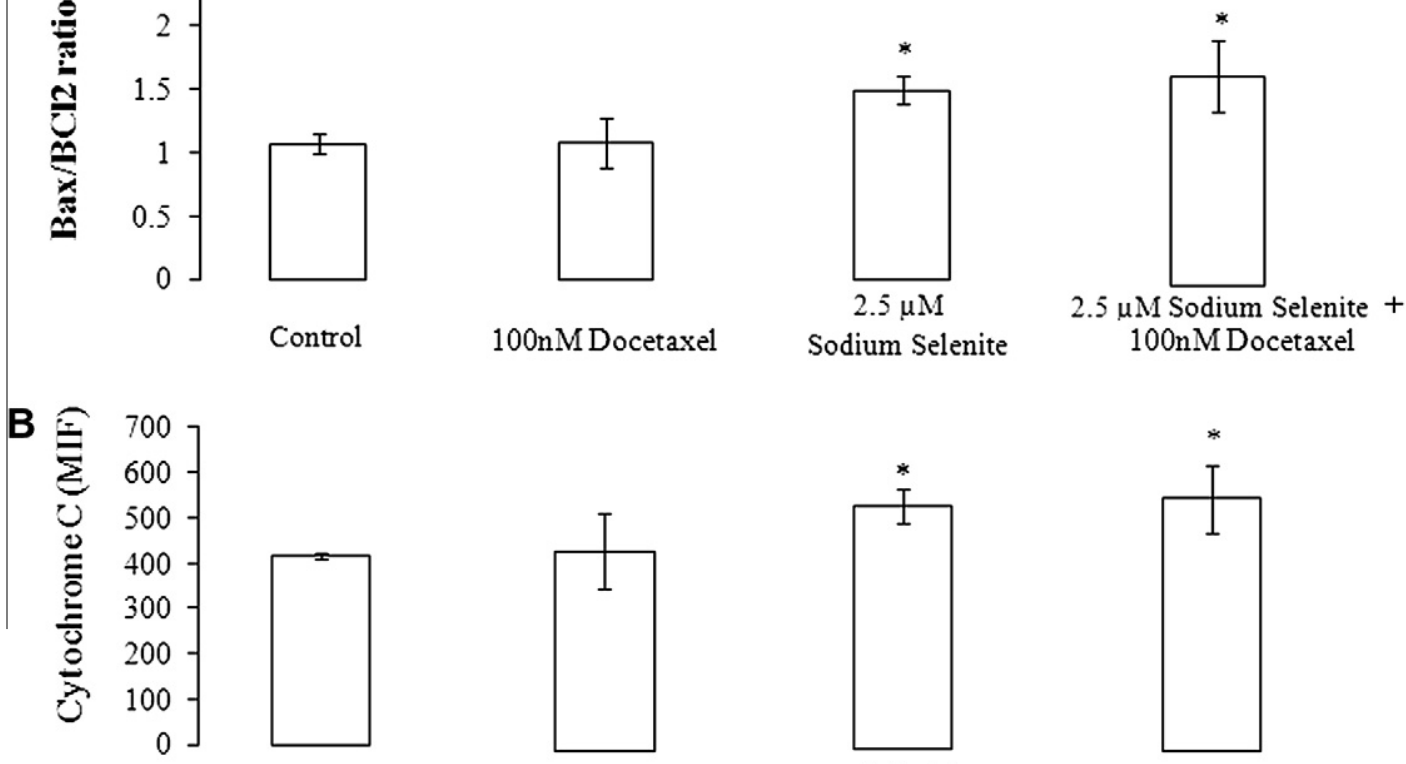

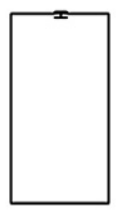

Control

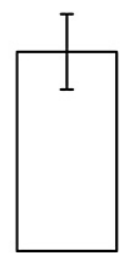

100nM Docetaxel

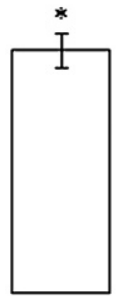

$2.5 \mu \mathrm{M}$

Sodium Selenite

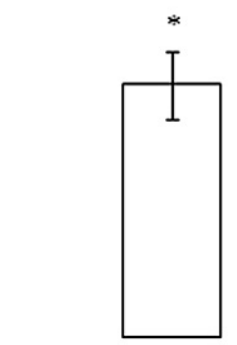

$2.5 \mu \mathrm{M}$ Sodium Selenite + 100nM Docetaxel

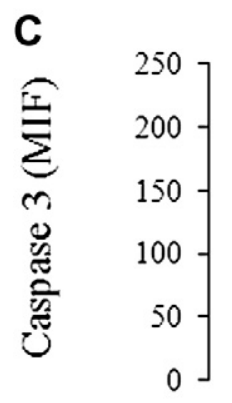

Control

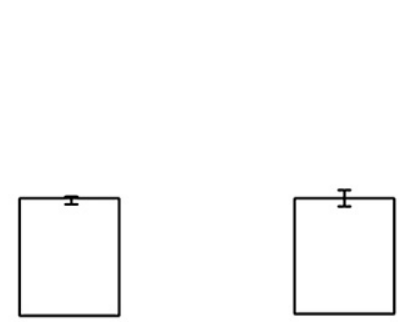

100nM Docetaxel

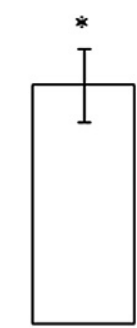

$2.5 \mu \mathrm{M}$ Sodium Selenite

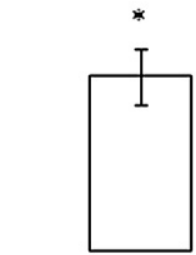

$2.5 \mu \mathrm{M}$ Sodium Selenite + 100nM Docetaxel

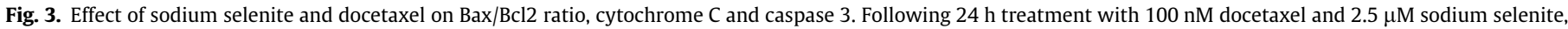

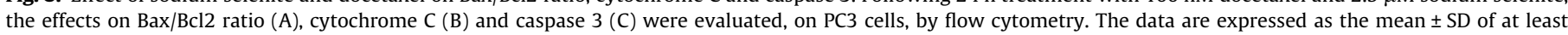
duplicate determinations $\left({ }^{*} p<0.05\right.$ vs control).

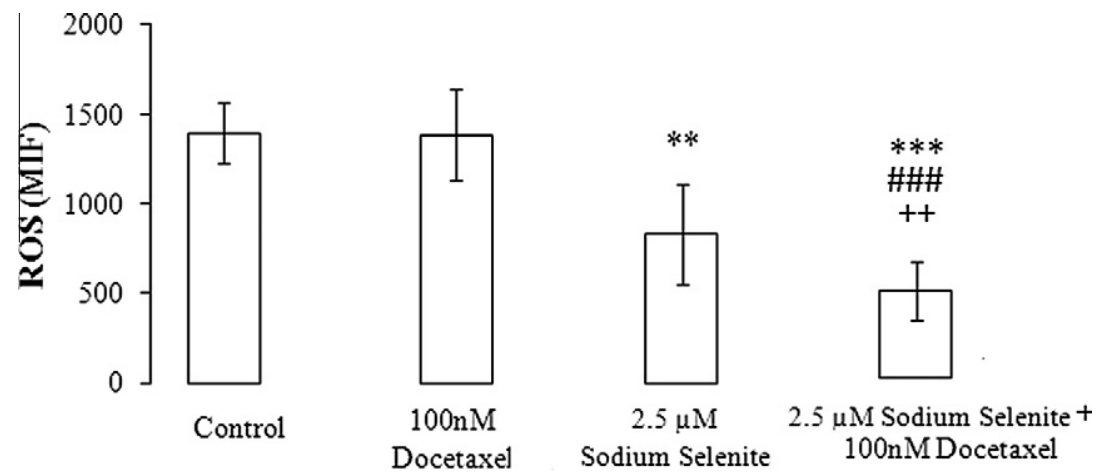

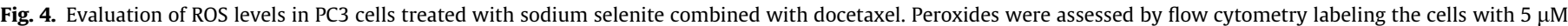

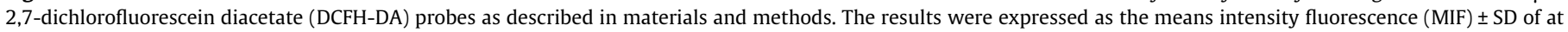

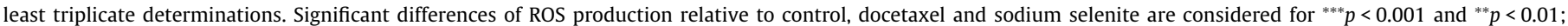
${ }^{\# \# \#} p<0.001$ and ${ }^{++} p<0.05$, respectively. 


\subsection{Docetaxel and sodium selenite induces cell cytotoxicity}

In order to examine if the anti-proliferative effect was accomplished by cell cytotoxicity, we analyzed cell viability and death by flow cytometry labeling the cells with Annexin-V/Propidium Iodide. Alive cells $(\mathrm{A})$ exclude propidium iodide and do not bind annexin-V. Apoptotic cells with intact membranes exclude propidium iodide, externalize phosphatidylserine to the outside of the plasma membrane and therefore bind Annexin V (IA) causing the apoptotic cell to emit fluorescence. Propidium iodide stains nuclear DNA of necrotic (N) and late apoptosis/necrosis cells (LA/ N).

Here we found that docetaxel and sodium selenite combination is more effective to induce cell cytotoxicity than either alone, playing an additive effect, and that cell death is mainly by apoptosis and apoptosis $v s$ necrosis (Fig. 2A). The results agree with $\Delta \psi \mathrm{m}$ depletion (Fig. 2B).

\subsection{Sodium selenite increases the expression of apoptotic signals}

$\mathrm{Bcl} 2$ and Bax are members of the Bcl2 family involved in apoptosis regulation, playing an antiapoptotic and proapoptotic role, respectively [26]. To analyze some of the mechanisms, which may participate in cell death induced by sodium selenite alone and in combination with docetaxel, we evaluate $\mathrm{Bax} / \mathrm{Bcl} 2$ ratio, cytochrome $C$ and caspase 3 expression. Fig. 3 indicates an increase in the apoptotic molecules, namely, cytochrome $C$ and caspase 3 as well in the $\mathrm{Bax} / \mathrm{Bcl} 2$ ratio, comparing to control.

\subsection{Sodium selenite and docetaxel induced-cytotoxicity is associated with peroxides depletion}

Next we test the hypothesis weather sodium selenite and docetaxel combination-induced cytotoxicity could be associated to ROS production. As shown in Fig. 4, sodium selenite alone and combined with docetaxel induced ROS depletion in PC3 cells, after 24 h treatment.

\section{Discussion}

Prostate cancer may develop from an androgen dependent stage responding to androgen ablation therapy and progresses to a further hormone refractory prostate cancer (HRPC) that is resistant to radiotherapy and chemotherapy, namely Taxotere (docetaxel) [4]. At this stage prostate cancer cells may have loose androgen receptor as occurs in PC3 cell line, derived from bone metastasis and therefore representing the advanced stages prostate cancer [10].

Lack of curative treatments underline the importance of additional trials for the development of a successful and effective therapeutic approach in prostate cancer. Sodium selenite has been recognized by its anticancer properties and its chemoprotective action [11].

Therefore we are interested to evaluate if sodium selenite and docetaxel combination results in a synergistic anticancer effect on prostate cancer cells that could also contribute to systemic toxicity reduction. Data not shown indicate that docetaxel has a higher antiproliferative effect on PC3 cells, compared to HPV10, from localized prostate adenocarcinoma and RWPE1, from normal prostate epithelium. Moreover, we confirm that docetaxel alone did not induce cell death $[9,11]$. Makarovskiy et al. [10] demonstrate that androgen independent cells, including PC3, develop resistance to docetaxel due to continuity of drug exposure.

On the other hand, we confirm that sodium selenite induced cell death in PC3, as previously documented, in other prostate cancer
Table 1

Effect of sodium selenite and docetaxel combination in PC3 cell cycle.

\begin{tabular}{|c|c|c|c|}
\hline Cell cycles (\%) & G0/G1 & G2M & $\mathrm{S}$ \\
\hline Control & 64.9 & 14.6 & 20.5 \\
\hline $100 \mathrm{nM}$ docetaxel $^{\mathrm{a}}$ & 17.2 & 63.5 & 19.3 \\
\hline $2.5 \mu \mathrm{M}$ sodium selenite ${ }^{\mathrm{a}}$ & 29.3 & 26.1 & 44.6 \\
\hline $100 \mathrm{nM}$ docetaxel $+2.5 \mu \mathrm{M}$ sodium selenite $\mathrm{a}^{\mathrm{a}}$ & 23.1 & 33.9 & 43 \\
\hline
\end{tabular}

a Significant alterations compared to control.

cells as DU145, LNCaP and LAPC-4 [12,13]. Moreover, our major findings indicate that sodium selenite and docetaxel, in combination, play a synergistic antiproliferative effect on prostate cancer (Fig. 1C) and an additive cytotoxic effect, mainly by apoptosis vs necrosis (Fig. 2A), in line with $\Delta \psi \mathrm{m}$ depletion (Fig. 2B).

Docetaxel and selenite inhibits cell growth (Fig. 1A and B), arresting cells to $\mathrm{G} 2 \mathrm{M}$ and $\mathrm{S}$ phase, respectively, in prostate cancer cells (Table 1 ) $[12,18,21]$.

We subsequent evaluated some molecules that could be involved in cell death signaling. Therefore we analyzed the expression of Bcl2 and Bax, playing an antiapoptotic and proapoptotic role, respectively. Bax targets the mitochondria to antagonize $\mathrm{Bcl} 2$ effect and promotes the release of cytochrome $\mathrm{C}$ that activates caspase 3 [26]. Sodium selenite, but not docetaxel, induces an increase in $\mathrm{Bax} / \mathrm{Bcl} 2$ ratio, cytochrome $\mathrm{C}$ and caspase 3 expression (Fig. 3) as demonstrated by others $[8,13,15]$. However, the augmented apoptotic $v s$ necrotic effect, resulting from drugs combination was not associated to an increase of $\mathrm{Bax} / \mathrm{Bcl} 2$ ratio cytochrome $C$ or caspase 3 expression. Here we observed cell death mainly by late apoptosis vs necrosis because, with the method we used for cell death detection, we can not distinguish between late apoptosis $v s$ necrosis. Despite, we have observed a decrease in $\Delta \psi \mathrm{m}$ in agreement with apoptosis. The necrotic contribution may be responsible for a discrete expression of the tested apoptotic molecules. However, other apoptotic pathways and proteins may be involved namely membrane or extrinsic apoptotic pathways (TNF receptors family as TRAIL receptors) or the Bcl2 family members. We also can not exclude the possible participation of autophagy cell death process.

These observations could be related with Yoo et al. [8] showing that docetaxel sensitizes PC3 apoptosis induced by TRAIL but does not induce significant changes in the intracellular levels of BCL-2. Variation in caspase 3 expression is only statistically significant when comparing to control. On account of that we obtained a significant increase of caspase 3 expression in cells treated with sodium selenite alone and in combination therapy. The decrease of caspase 3 expression in the cells treated with the combined therapy, comparing to sodium selenite alone, is not statistically significant.

On the other hand cell death may be related with oxidative stress induction. In fact docetaxel has been recently associated to an increase of ROS in the prostate cancer DU-145 cells [27]. Surprisingly, we found ROS depletion after $24 \mathrm{~h}$ treatment (Fig. 4). Moreover, it could be a result of peroxides conversion into hydroxyl radicals. However, data not shown indicate that sodium selenite and docetaxel alone, or in combination, did not interfere on PC3 peroxides production after $6 \mathrm{~h}$ treatment. Therefore, we admit that sodium selenite could inhibit the antioxidant system leading to oxidative lesion by reactive hydroxyl radicals and consequent cell death.

Xiang et al. [15] and Li et al. [14] show that sodium selenite induces apoptosis by generation of superoxide radicals in the LNCaP. Sodium selenite alters subcellular distribution of manganese superoxide dismutase (MnSOD), another important antioxidant defense, inducing its depletion in mitochondria and increase in cytosol [17]. MnSOD converts superoxide radical into hydrogen, 
likewise, its depletion in the mitochondrial matrix, may result in inefficient dismutation of superoxide anion into hydrogen peroxide, contributing to the observed peroxides reduction. Moreover it could explain the increased levels of superoxide anion described by Li et al. [14]. MnSOD overexpression has also been associated to apoptosis resistance induced by sodium selenite [15].

Reduced glutathione (GSH), counteract oxidative stress by directly quenching reactive oxygen species and has been associated to resistance to apoptosis and radiation in prostate cancer cells [28]. Besides sodium selenite supplies selenium for synthesis of seleno-proteins such as the antioxidant defenses glutathione peroxidase (Gl-Px) and thioredoxin reductase, higher concentrations are related with increased oxidative stress by decreasing reduced glutathione/oxidized glutathione (GSH/GSSG) ratio and also by altering MnSOD subcellular distribution. These observations are related with an increase of ROS levels and cell sensitization to apoptosis [13-15,29].

Moreover the increase in $\mathrm{Bax} / \mathrm{Bcl} 2$ ratio, cytochrome $\mathrm{C}$ expression, decrease in mitochondria membrane potential, as well as the increase in ROS production and the depletion in MnSOD and GSH/GSSG ratio, as demonstrated by others [13,15,17], reinforce the contribution of mitochondria on sodium selenite induced apoptosis. Other intracellular apoptotic pathways must be also activated by docetaxel and sodium selenite combination, supporting that a multitude of cell targets may constitute a new strategy to overcome drug resistance and may contribute to reduce systemic toxicity.

Here we can conclude that sodium selenite and docetaxel play a synergistic antiproliferative effect and significantly induced cell death, mainly by late apoptosis vs necrosis, which is correlated with $\Delta \psi$ m depletion.

These results may be related with cell cycle arrest (Table 1 ) and/ or with the production of other ROS species, besides peroxides, namely, hydroxyl radical or superoxide anion (not measured).

Each drug contribute to cell cycle arrest in agreement with the observed anti proliferative effect. However, while, docetaxel induces G2M arrest, sodium selenite, alone or in combination induces $\mathrm{S}$ phase arrest. On the other hand, the decrease in peroxides levels may be related with its conversion into hydroxyl radical. Moreover it may be a result of a decrease in the dismutation of superoxide anion.

These findings suggest that docetaxel and sodium selenite combination may be more effective on prostate cancer treatment than docetaxel alone warranting further evaluation as a new cancer therapeutic approach.

Moreover, this association, by lowering drug concentration may be also useful in reducing drug side effects related with systemic toxicity.

\section{Acknowledgments}

This work was supported by the CIMAGO - Centre of Investigation in Environment, Genetics and Oncobiology, Faculty of Medicine, University of Coimbra (Grants CIMAGO 14/05 and CIMAGO 3/06) and the Fundação para a Ciência e a Tecnologia (FCT), Portugal (Grant SFRH/BD/40215/2007).

\section{References}

[1] A. Jemal, R. Siegal, J. Xu, et al., Cancer statistics, C.A. Cancer J. Clin. 60 (5) (2010) 277-300.
[2] M.P. Coleman, M. Quaresma, F. Berrino, et al., Cancer survival in five continents: a worldwide population-based study (CONCORD), Lancet Oncol. 9 (2008) 730-756.

[3] G. Sonpavde, T.E. Huston, W.R. Berry, Hormone refractory prostate cancer: management and advances, Cancer Treat. Rev. 32 (2006) 90-100.

[4] B. Schurko, W.K. Oh, Docetaxel chemotherapy remains the standard of care in castration-resistant prostate cancer, Nat. Clin. Pract. Oncol. 5 (9) (2008) 506507.

[5] P.B. Schiff, S.B. Horowitz, Taxol stabilizes microtubules in mouse fibroblast cells, Proc. Natl. Acad. Sci. 77 (1980) 1561-1565.

[6] C.A. Stein, Mechanisms of action of taxanes in prostate cancer, Semin. Oncol. 26 (5 Suppl. 17) (1999) S3-S7.

[7] Y. Li, X. Li, M. Hussain, et al., Regulation of microtubule, apoptosis, and cell cycle - related genes by taxotere in prostate cancer cells analyzed by microarray, Neoplasia 6 (2) (2004) 158-167.

[8] J. Yoo, S.-S. Park, Y.J. Lee, Pretreatment of docetaxel enhances TRAIL mediated apoptosis in prostate cancer cells, J. Cell. Biochem. 104 (2008) 1636-1646.

[9] Y. Li, M. Hussain, S.H. Sarkar, et al., Gene expression profiling revealed novel mechanism of action of taxotere and furtulon in prostate cancer cells, B.M.C. Cancer 5 (2005) 7-14.

[10] A.N. Makarovskiy, E. Siryaporn, D.C. Hixson, et al., Survival of docetaxelresistant prostate cancer cells in vitro depends on phenotype alterations and continuity of drug exposure, Cell. Mol. Life Sci. 59 (2002) 1198-1211.

[11] N. Nadiminty, A.C. Gao, Mechanisms of selenium chemoprevention, therapy in prostate cancer, Mol. Nutr. Food Res. 52 (2008) 1247-1260.

[12] D.G. Menter, A.L. Sabichi, S.M. Lippman, Selenium effects on prostate cell growth, Cancer Epidemiol. Biomarkers Prev. 9 (2000) 1171-1182.

[13] B. Husbeck, D.M. Peehl, S.J. Knox, Redox modulation of human prostate carcinoma cells by selenite increases radiation-induced cell killing, Free Radic. Biol. Med. 38 (1) (2005) 50-57.

[14] G.-X. Li, H.H. Hu, C. Jiang, et al., Differential involvement of reactive oxygen species in apoptosis induced by two classes of selenium compounds in human prostate cancer cells, Int. J. Cancer 120 (2007) 2034-2043.

[15] N. Xiang, R. Zhao, W. Zhong, Sodium selenite induces apoptosis by generation of superoxide via the mitochondrial-dependent pathway in human prostate cancer cells, Cancer Chemother. Pharmacol. 63 (2) (2009) 351-362.

[16] S. Reagan-Shaw, M. Nihal, H. Ahsan, et al., Combination of vitamin E and selenium causes an induction of apoptosis of human prostate cancer cells by enhancing Bax/Bcl2 ratio, Prostate 68 (2008) 1624-1634.

[17] L. Guan, Q. Jiang, Z. Li, et al., The subcellular distribution of MnSOD alters during sodium selenite-induced apoptosis, B.M.B. Rep. 42 (6) (2009) 361366.

[18] C. Jiang, Z. Wang, H. Ganther, et al., Distinct effects of methylseleninic acid versus selenite on apoptosis, cell cycle, and protein kinase pathways in DU145 human prostate cancer cells, Mol. Cancer Ther. 1 (12) (2002) 1059-1066.

[19] M.E. Kaighn, K.S. Narayan, Y. Ohnuki, et al., Establishment and characterization of a human prostatic carcinoma cell line (PC3), Invest. Urol. 17 (1979) 16-23.

[20] M.C. Alley, D.A. Scudiero, A. Monks, et al., Feasibility of drug screening with panels of human tumor cell lines using a microculture tetrazolium assay, Cancer Res. 48 (1988) 589-601.

[21] M. Mimeault, S.L. Johansson, G. Vankatraman, et al., Combined targeting of epidermal growth factor receptor and hedgehog signaling by gefitinib and cyclopamine cooperatively improves the cytotoxic effects of docetaxel on metastatic prostate cancer cells, Mol. Cancer Ther. 6 (3) (2008) 967-978.

[22] W. Cao, K.T. Shiverick, K. Namiki, et al., Docetaxel and bortezomid down regulate $\mathrm{Bcl}-2$ and sensitize $\mathrm{PC}-3-\mathrm{Bcl}-2$ expressing prostate cancer cells to irradiation, World J. Urol. 26 (5) (2008) 509-516.

[23] A.A. Boldyrev, Discrimination between apoptosis and necrosis of neurons under oxidative stress, Biochemistry (Moscow) 65 (2000) 834-842.

[24] A. Cossariza, M. Baccarini-Contri, G. Kalashnikova, et al., A new method for the cytofluorimetric analysis of mitochondrial membrane potential using $\mathrm{J}$ aggregate forming lipophilic cation 5,5',6,6'-tetrachloro-1, $1^{\prime}, 3,3^{\prime}$ tetraethylbenzimidazolcarbocyanine iodide (JC-1), Biochem. Biophys. Res. Commun. 197 (1993) 40-45.

[25] G. Rothe, G. Valet, Flow cytometric analysis of respiratory burst activity in phagocytes with hydroethidine and 2,7 dichlorofluorescein, J. Leukoc. Biol. 47 (5) (1990) 440-448.

[26] J.M. Adams, S. Cory, The Bcl2 family: arbiters of cell survival, Science 281 (1998) 1322-1326.

[27] T. Rabi, A. Bishayee, $d$-Limonene sensitizes docetaxel-induced cytotoxicity in human prostate cancer cells: generation of reactive oxygen species and induction of apoptosis, J. Carcinog. 8 (1) (2009) 1-9.

[28] R.N.T. Coffey, R.W.G. Watson, N.J. Hegarty, et al., Thiol mediated apoptosis in prostate carcinoma cells, Cancer 88 (9) (2000) 2092-2104.

[29] E.N. Drake, Cancer chemoprevention: selenium as a pro-oxidant, not an antioxidant, Med. Hypotheses 67 (2006) 318-322. 